\title{
Evaluación de la presencia de bacterias patógenas en aerosoles generados por piezas de alta velocidad
}

Evaluation of the presence of pathogenic bacteria in aerosols generated by high-speed parts

Avaliação da presença de bactérias patogênicas em aerossóis gerados por peças de alta velocidade

\section{Sonia Elena Pineda Higuita ${ }^{1}$ Edwin J. Meneses Gómez ${ }^{2}$ Laura Giraldo Quintero ${ }^{3}$}

Recibido: 12 de octubre de 2020

Aprobado: 2 de agosto de 2021 Publicado: 6 de septiembre de 2021

Cómo citar este artículo:

Pineda-Higuita SE, Meneses-Gómez EJ, Giraldo-Quintero L. Evaluación de la presencia de bacterias patógenas en aerosoles generados por piezas de alta velocidad. Revista Nacional de Odontología. (2021); 17(1), 1-11. doi: https://doi.org/10.16925/2357-4607.2021.01.06

Artículo de investigación. https://doi.org/10.16925/2357-4607.2021.01.06

1 Fundación Universitaria Autónoma de las Américas, Colombia. ORCID: https://orcid.org/0000-0003-0309-5714

Grupo de Investigación en Salud y Comunidad.

Correo electrónico: edwin.meneses@uam.edu.co

2 Fundación Universitaria Autónoma de las Américas, Colombia. ORCID: https://orcid.org/0000-0002-1428-3297

3 Fundación Universitaria Autónoma de las Américas, Colombia. ORCID: https://orcid.org/0000-0002-2157-0972 


\title{
Resumen
}

Introducción: la identificación de bacterias patógenas generadas por los aerosoles de las piezas de alta es importante porque permite conocer el ambiente de trabajo odontológico, los procesos de desinfección y los riesgos a los que está expuesto el personal responsable y beneficiario de la práctica de la odontología.

Objetivo: determinar la presencia de bacterias patógenas en aerosoles generados por las piezas de mano de alta velocidad en una clínica odontológica.

Materiales y métodos: estudio descriptivo de corte trasversal en el cual se evaluó la presencia de bacterias patógenas generadas por las piezas de mano de alta velocidad. Se evaluaron 42 unidades odontológicas seleccionadas al azar que estuviesen siendo utilizadas en actividades clínicas generadoras de aerosoles. Se empleó la técnica de sedimentación en placas para el estudio microbiológico del ambiente.

Resultados: en los procedimientos de operatoria se observó crecimiento en un 31,0, seguido por la profilaxis en un un 11,9 y la endodoncia en un 9,5. En las muestras analizadas predominaron las bacterias Gram positivas: Staphylococcus sp en un 40,7, Streptococcus sp en un 11,1, Bacilos gram positivos en un 25,9 y Micrococcus sp con 3,7 .

Conclusión: la pieza de alta aumenta la cantidad de aerosoles durante los procedimientos de operatoria, seguido por la profilaxis. Las bacterias que se encontraron en mayor cantidad corresponden a cocos Gram positivos tipo Staphylococcus sp. Sin embargo, las condiciones de calidad de la clínica son adecuados, es importante seguir fortaleciendo todos los procesos y procedimientos que conllevan a una prestación del servicio bajo parámetros de bioseguridad.

Palabras clave: aerosoles, bacterias, odontología.

\author{
Abstract \\ Introduction: The identification of pathogenic bacteria generated by the aerosols of the high parts is important \\ because it allows to know the dental work environment, the disinfection processes and the risks to which the \\ dental staff is exposed.
}

Objective: Determine the presence of pathogenic bacteria in aerosols generated by high-speed handpieces in a dental clinic.

Methods: Descriptive cross-sectional study in which the presence of pathogenic bacteria generated by high-speed handpieces was evaluated. 42 randomly selected dental units were evaluated, which were being used in clinical aerosol generating activities. The plate sedimentation technique was used for the microbiological study of the environment.

Results: In the operating procedures, growth was observed in 31.0, followed by prophylaxis in 11.9 and endodontics in 9.5. In the analyzed samples, gram positive bacteria predominated: Staphylococcus sp in 40.7, Streptococcus sp in 11.1, gram positive bacilli in 25.9 and Micrococcus sp with 3.7.

Conclusion: The high part increases the amount of aerosols during the operating procedures, followed by prophylaxis. The bacteria that were found in greater quantity correspond to gram positive cocci type Staphylococci sp. However, the quality conditions of the clinic are adequate, it is important to continue strengthening all the processes and procedures that lead to the provision of the service under biosafety parameters.

Key words: aerosols, bacteria, dentistry. 


\section{Resumo}

Introdução: A identificação de bactérias patogênicas geradas pelos aerossóis das partes altas é importante, pois permite conhecer o ambiente de trabalho odontológico, os processos de desinfecção e os riscos a que estão expostos o pessoal responsável e beneficiário da prática odontológica.

Objetivo: Determine a presença de bactérias patogênicas em aerossóis gerados por peças de mão de alta velocidade em uma clínica odontológica.

Materiais e métodos: Estudo transversal descritivo, no qual foi avaliada a presença de bactérias patogênicas geradas por peças de mão de alta velocidade. Foram avaliadas 42 unidades odontológicas randomizadas que estavam sendo utilizadas em atividades clínicas geradoras de aerossóis. A técnica de sedimentação de placas foi utilizada para o estudo microbiológico do ambiente.

Resultados: Nos procedimentos operacionais, observou-se crescimento em 31,0, seguido de profilaxia em 11,9 e endodontia em 9,5. Nas amostras analisadas predominaram bactérias gram-positivas: Staphylococcus $\mathrm{sp}$ em 40,7, Streptococcus sp em 11,1, bacilos Gram-positivos em 25,9 e Micrococcus sp com 3,7.

Conclusão: A parte alta aumenta a quantidade de aerossóis durante os procedimentos operacionais, seguida pela profilaxia. As bactérias encontradas em maior quantidade correspondem aos cocos Gram-positivos do tipo Staphylococcus sp. No entanto, como as condições de qualidade da clínica são adequadas, é importante continuar fortalecendo todos os processos e procedimentos que levam à prestação do serviço sob parâmetros de biossegurança.

Palavras-chave: aerossóis; bactérias; odontologia.

\section{Introducción}

Los profesionales odontólogos, los auxiliares de apoyo a la práctica profesional de la odontología, al igual que otros profesionales del área de la salud trabajan en ambientes altamente contaminados y los diferentes procedimientos que realizan a diario los exponen a todo tipo de riesgo físico, químico, ergonómico y biológico. En los procedimientos de rutina propia de la práctica odontológica clínica que implican la preparación de los dientes, los procedimientos de remoción de materiales en boca como las incrustaciones, el uso de jeringas de agua, aire y salpicaduras, generan aerosoles que representan un riesgo alto para el profesional, pero también para los pacientes. La composición del aerosol difiere de un paciente a otro de acuerdo con la naturaleza del procedimiento, así como con la preparación del diente (1).

Los aerosoles generados por la pieza de alta generalmente tienen un diámetro de 5 micras o menos y pueden permanecer suspendidas en el aire (2).

Las fases sólidas y líquidas de un aerosol están compuestas por bacterias, elementos sanguíneos, virus y partículas orgánicas de tejido, diente, saliva y desechos. La cantidad de contaminación del aerosol depende de la calidad de la saliva, las secreciones nasales y de la garganta, la sangre, la placa dental y la presencia o ausencia de cualquier infección dental al cual está expuesto el personal de odontología (3). 
Los aerosoles que contienen microbios de la cavidad bucal del paciente se crean cuando se utilizan modernos instrumentos giratorios de alta velocidad en odontología restauradora. ¿Hasta qué punto estos aerosoles pueden generar propagación de partículas y qué nivel de contaminación causan en la práctica de la odontología e incluso en cirugía dental? (4).

La orofaringe es el sitio principal de colonización de patógenos respiratorios potenciales y el biofilm oral actúa como reservorio para estos patógenos (5).

Estudios indican que el escalador ultrasónico es el mayor productor de aerosol y salpicadura, además refieren que el efecto de cavitación durante los procedimientos quirúrgicos produce una cantidad significativa de aerosol por el líquido refrigerante en el proceso de lavado de sangre y proporciona visibilidad óptima al campo de operación (6).

En una unidad odontológica el agua juega diferentes y muy variados roles que van desde el enfriamiento de equipos hasta el enjuague bucal. El equipamiento se encuentra usualmente acoplado mediante un sistema de tuberías, generalmente de plástico u otro material sintético que se alimentan de un depósito de agua o está directamente conectado a la red de suministro de agua potable de la instalación. E empleo de muchos de estos equipos como es el caso de los micromotores de alta velocidad genera una gran cantidad de aerosoles (7).

Los procedimientos dentales contribuyen al aumento de la contaminación bacteriana con la posible contaminación por salpicaduras y diseminación de aerosoles, que sigue siendo un peligro significativo tanto para el de operador odontólogo como para los pacientes (8).

Las líneas de agua de la unidad dental contribuyen a la contaminación de aerosoles debido al diámetro estrecho, estancamiento de agua, calentamiento de la silla dental, falla de la válvula anti-retracción y contaminación de las botellas del depósito. Además, la unidad tiene un tubo de plástico que conduce a la formación de la biopelícula que libera un gran número de organismos (9).

Los profesionales de la salud conocen de la importancia de la utilización de las medidas de bioseguridad y las implicaciones que tiene el no hacer uso adecuado de ellas. Sin embargo, existen factores propios de su labor profesional que lo convierten en personas con alto grado de vulnerabilidad al riesgo de infección, ya que la cavidad bucal es un medio propicio para albergar diferentes agentes patógenos como bacterias, hongos, parásitos y virus que al ser propulsados en forma de aerosoles por los instrumentos rotatorios se convierten en agentes patógenos en el ambiente que pueden causar diferentes enfermedades. 
Los aerosoles permanecen en el aire por un largo tiempo incluso después de la finalización del procedimiento dental y tienen el riesgo potencial de ingresar a las vías respiratorias. La salpicadura se evapora, dejando partículas más pequeñas llamadas núcleos de gotitas que pueden transportar bacterias y virus y transmitir diversas enfermedades como el Síndrome Respiratorio Agudo Severo (SARS) y la tuberculosis (3).

La concentración de aerosoles bacterianos también depende de factores ambientales como el contenido microbiano del aire exterior el tipo de ventilación y la presencia de humedad en el ambiente interior $(10,11)$.

Estos argumentos planteados y evidenciados en la literatura científica generaron la necesidad de plantear esta propuesta de investigación cuyo objetivo fue determinar la presencia de bacterias patógenas en aerosoles generados por las piezas de mano de alta velocidad en una clínica odontológica de la ciudad de Medellín durante el año 2019.

\section{Materiales y métodos}

\section{Tipo de estudio}

Se realizó un estudio descriptivo de corte trasversal con un enfoque cuantitativo. La muestra estuvo constituida por 42 unidades odontológicas donde se ubicaron los medios de cultivo. Como criterios de inclusión se tuvieron en cuenta los siguientes: unidades odontológicas de los estudiantes de los semestres $8^{\circ}, 9^{\circ}$ y $10^{\circ}$, en los cuales se realizaba actividad clínica generadora de aerosoles. Como criterios de exclusión se consideraron unidades odontológicas que por condiciones técnicas se encontraban fuera de servicio y cubículos donde se realizaran procedimientos que no generaran aerosoles.

\section{Recolección de la muestra}

Para la recolección de la muestra se tuvo como referencia las recomendaciones de la guía Técnica Colombiana NTC 5230 expedida por el ICONTEC, la cual contiene las instrucciones para el estudio microbiológico de superficies ambientes y manos.

\section{Elementos de protección para la toma de la muestra}

Previamente se creó un protocolo de toma de muestra que incluía como primer paso la colocación de elementos de protección personal. Quien se encontraba a cargo de 
la toma de la muestra utilizó los siguientes implementos: guantes, tapabocas, gorro y bata. Con autorización del paciente, auxiliar y operador, la recolección de la muestra fue realizada por el método de sedimentación, en el cual los medios de cultivos se exponían al ambiente por un tiempo determinado. Ninguno de los pacientes en consulta fue sometido a enjuague con colutorios preoperatorios. Una vez se seleccionaron las unidades que cumplieron con los criterios de inclusión, se marcaron los medios de cultivo con el número del piso, número del cubículo, tipo de procedimiento, tipo de paciente y fecha de la toma de la muestra. Durante la atención del paciente se dejaron abiertos los medios de cultivo (agar sangre, EMB y MacConkey) por un período de 10 minutos en áreas de aproximadamente $10 \times 10 \mathrm{~cm}^{2}$, a una distancia de aproximadamente 50 centímetros del paciente y del odontólogo, al cabo de este tiempo se cerraron los medios y se procedió con el envío al laboratorio de ciencias básicas para su análisis. El traslado de las muestras al laboratorio se realizó en el menor tiempo posible para evitar contaminaciones cruzadas.

\section{Procesamiento de las muestras}

Las muestras fueron recolectadas y se incubaron en estufa bacteriológica a $37^{\circ} \mathrm{C}$. Se revisó el crecimiento a las 24 horas, aquellos medios que no revelaron crecimiento se incubaron otras 24 horas a $37^{\circ} \mathrm{C}$. El análisis microbiológico se realizó de forma manual, se tomó la placa de Petri y se dividió en 4 cuadriculas y se realizó el conteo de las colonias. Además, se realizaron extendidos en láminas portaobjeto, posteriormente se colorearon con Gram y se visualizaron al microscopio, también se realizaron pruebas de catalasa para diferenciar estafilcocos de estreptococos, prueba de coagulasa para diferenciar S. aureus de las demás especies de estafilococos. Para el control de calidad se utilizó una cepa certificada ATCC® Staphyloccus aureus $25923^{\text {TM }}$

\section{Análisis de la información}

Se construyó una base de datos en Excel donde se registraron cada una de las variables con sus respectivas categorías naturaleza y su nivel de medición. Dichas variables se analizaron mediante el programa estadístico EPIDAT 4.2 y se calcularon frecuencias y porcentajes para las variables cualitativas y medidas de posición. Para las variables cuantitativas, se analizaron media y deviación estándar, se hizo además un análisis bivariado mediante la prueba de $\mathrm{Chi}^{2}$ con la cual se evaluó si existían diferencias estadísticas significativas entre el pisos y el crecimiento; el crecimiento y tipo de procedimiento; y entre el tipo de paciente y clase de microorganismo. 
Esta investigación fue clasificada según la resolución 8430 de 1993 como investigación de sin riesgo y no consideró ningún tipo de intervención en humanos. Todo el material utilizado y los microorganismos aislados se eliminaron teniendo en cuenta todos los protocolos de bioseguridad establecidos para este tipo de procedimiento.

\section{Resultados}

Se analizaron 42 muestras de las cuales 5 correspondieron a placas control, las cuales resultaron negativos. De los 37 restantes se obtuvo crecimiento en 22 lo cual correspondió al 52,4.

Las unidades evaluadas se encontraban ubicadas en los pisos 7 y 9 . Aunque se obtuvieron resultados muy similares en el piso 9, se obtuvo crecimiento en el 28,6 (12) y en el piso 7 un crecimiento del 23,8 (10). No se encontraron diferencias estadísticas significativas entre el piso donde se ubica la unidad y el crecimiento del microorganismo ( $p>0,05)$.

Respecto a los procedimientos en los cuales se obtuvo mayor crecimiento fue en el de operatoria con un 31,0 (13) seguido por la profilaxis con un 11,9 (5) y la endodoncia en un 9,5 (4). No se hallaron diferencias estadísticas significativas entre el crecimiento y el tipo de procedimiento $(p>0,05)$.

En las muestras analizadas predominaron las bacterias Gram positivas: Staphylococcus sp en un 40,7 (11), Streptococcus sp en un 17,1 (3), Bacilos gram positivos en un 25,9 (7) y Micrococcus sp con 3,7 (1) (figura 1). 


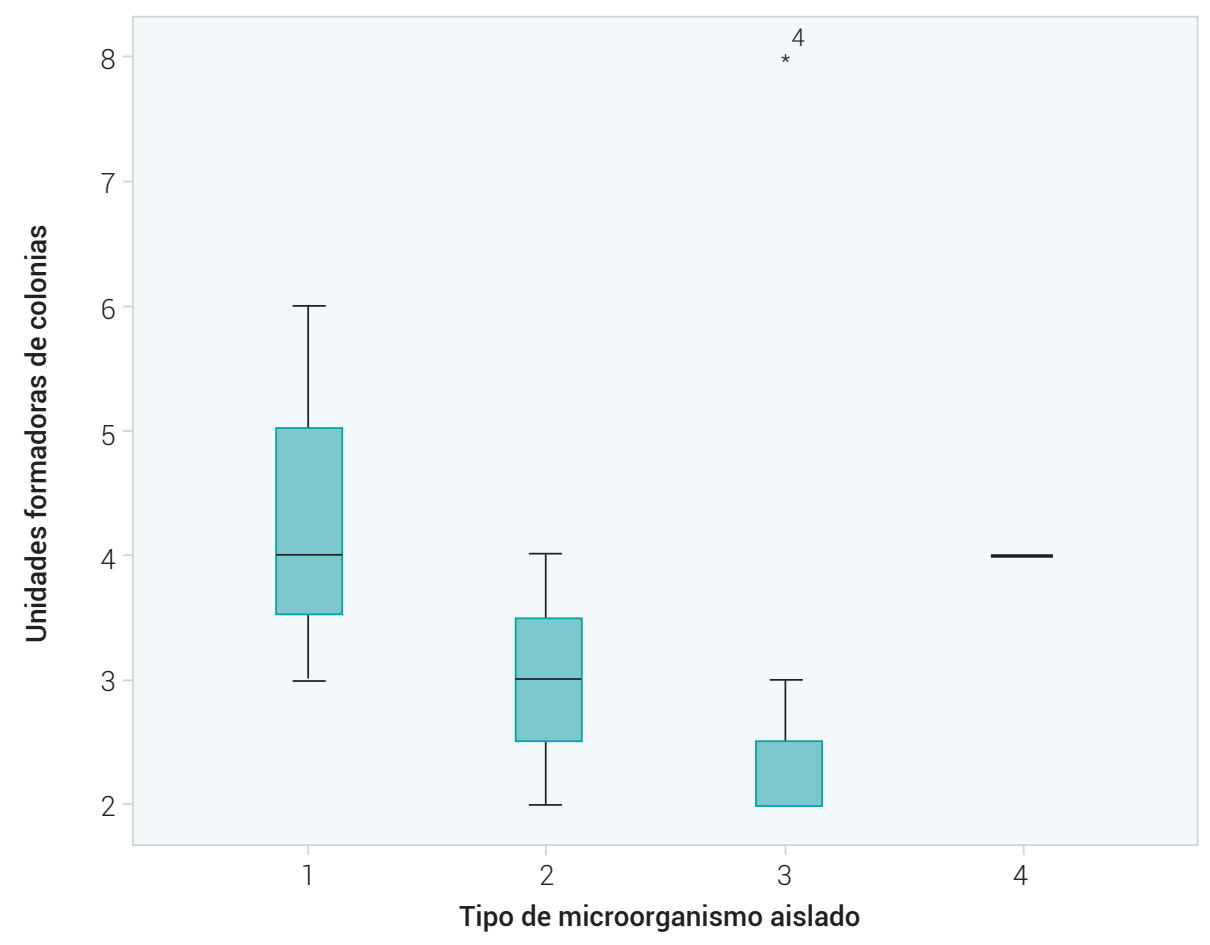

Figura 1. Tipo de microorganismo aislado

Fuente: elaboración propia.

Además, se observó que, en cuanto al tipo de paciente atendido, el crecimiento fue mayor para el caso de los adultos en comparación con los niños y se encontraron diferencias estadísticas significativas entre el tipo de paciente y el microoganismo $(p=0,001)$.

El promedio de unidades formadoras de colonia fue de 3,68 UFC y un crecimiento mínimo de 2 colonias y un máximo de 8 UFC.

\section{Discusión}

De acuerdo con los resultados obtenidos en el estudio, permite reconocer que las bacterias obtenidas de los aerosoles generados en la consulta odontológica son una puerta de entrada para contaminación cruzada en superficies cercanas a la atención, incluso en los mismos elementos de protección personal como tapabocas y bata, como lo afirma el estudio piloto de Veena HR, et al. (1).

Con lo anterior, la Asociación Dental Americana, publica en su revista un estudio de Bentley CD, en donde se afirma que, a pesar de la rigurosa barrera de protección personal, el personal odontológico está expuesto a importante difusión de 
salpicaduras y aerosoles, contrastado con el presente estudio que permite evidenciar que más de la mitad de placas analizadas obtuvo crecimiento bacteriano (2).

Por otra parte, las bacterias que se encontraron en mayor proporción fueron del género Staphylococcus este se caracteriza por tener una pared más gruesa que las bacterias Gram negativas lo que le proporciona mayor tolerancia a la desecación y sobrevivir por más tiempo (11).

Además, se encontraron microorganismo del género Estreptococos, hallazgos similares a los encontrados por Rautema en su investigación en la cual evaluaron muestras tomadas del personal de odontología y superficies en salas dentales donde se utiliza la pieza de alta velocidad (12).

En los procedimientos odontológicos donde se utiliza la pieza de alta se genera gran cantidad de aerosoles, como es el caso de los procedimientos de operatoria donde no hay pasos para la desinfección, en comparación con la endodoncia donde sí se utiliza el hipoclorito durante el proceso. Es importante que el profesional tenga en cuenta todas las medidas de bioseguridad que protejan no solo al profesional sino también al paciente. Es necesario tener un control más estricto de la higiene del área de limpieza dentaria a intervenir para evitar posibles contaminaciones.

Las patologías de los adultos son más crónicas al tener dientes permanentes en comparación con los niños con tienen dientes temporales que en determinado momento se van a reemplazar.

A pesar de que la calidad del aire de la clínica no se ve afectada por grandes cantidades de bacterias generadas por los aerosoles de la pieza de alta velocidad, estos aerosoles deben controlarse en la mayor medida posible, para garantizar la salud de los pacientes y equipo dental en entornos de trabajo clínico.

La composición cuantitativa de los aerosoles dentales probablemente varía con cada paciente y sitio operatorio. La presencia de agentes bacterianos y el recuento de las Unidades Formadoras de Colonias (UFC) puede estar influenciado por el tipo de procedimiento que se puede llevar acabo en el área odontológica.

\section{Conclusiones}

En los aerosoles generados por las piezas de mano de alta velocidad en una clínica odontológica de la ciudad de Medellín se confirmaron bacterias en mayor cantidad correspondiente a cocos gram positivos tipo Staphylococcus. La pieza de alta velocidad aumenta la cantidad de aerosoles durante los procedimientos de operatoria, seguido por la profilaxis, y se evidencia mayor crecimiento de microrganismos en la atención del paciente adulto. Es necesario realizar más estudios y con un tamaño 
de muestra mayor que permitan definir unos métodos ideales para el control de las infecciones que se puedan generar en la prestación del servicio odontológico.

Las condiciones de calidad de la clínica son adecuadas, es importante seguir fortaleciendo todos los procesos y procedimientos que conllevan a una prestación del servicio bajo parámetros de bioseguridad y calidad.

Se hace necesaria la implementación de protocolos de desinfección previos a la atención odontológica e incluso la utilización de colutorios como enjuagues bucales de Clorhexidina que han demostrado eficacia en la reducción bacteriana de la cavidad bucal lo que permite procedimientos más seguros (13).

\section{Conflicto de interés}

Los autores informan no tener ningún conflicto de interés.

\section{Referencias}

1. Veena HR, Mahantesha S, Preethi A. J, Sudhir R, P, Suvarna H. P. Dissemination of aerosol and splatter during ultrasonic scaling: A pilot study. Journal of Infection and Public Health. 2015; 8:260-265. doi: https://doi.org/10.1016/j.jiph.2014.11.004.

2. Bentley CD, Burkhart NW, Crawford JJ. Evaluación de salpicaduras y contaminación de aerosoles durante procedimientos dentales. The Journal of the American Dental Association. 1994;125(5):579-584. doi: https://doi.org/10.14219/jada.archive.1994.0093.

3. Harrel SK, Barnes JB, Rivera-Hidalgo F. Aerosol and splatter contamination from the operative site during ultrasonic scaling. J Am Dent Assoc. 1998; 129(9):1241-9. doi: https://doi. org/10.14219/jada.archive.1998.0421

4. Kobza, JS Pastuszka, E Brągoszewska. ¿Las exposiciones a aerosoles representan un riesgo para los profesionales de la odontología? Medicina ocupacional. 2018; 68(7):454-458. doi: https://doi.org/10.1093/occmed/ kqy095

5. Checchi L, Montevecchi M, Moreschi A, Graziosi F, Taddei P, Violante FS. Efficacy of three face masks in preventing inhalation of airborne contaminants in dental practice. The Journal of the American Dental Association. 2005; 136(7):877-882. doi: https://doi.org/10.14219/jada. archive.2005.0288. 
6. Sawhney A, Venugopal S, Babu GR, Garg A, Mathew M, Yadav M, Gupta B, Tripathi S. Aerosols How Dangerous They Are in Clinical Practice. Journal of Clinical and Diagnostic Research. 2015; 9(4): ZC52-ZC57J. doi: https://doi.org/10.7860/JCDR/2015/12038.5835.

7. Bernard Polednik. Aerosol and bioaerosol particles in a dental office. Environmental Research. 2014; (134):405-409. doi: https://dx.doi.org/10.1016/j.envires.2014.03.027.

8. Freeman J. Risk of aerosol contamination around the dental chair. Dental Nursing. 2013; 9(1):12-5. doi: https://doi.org/10.12968/denn.2013.9.1.12.

9. Montebugnoli L, Chersoni S, Prati C, Dolci G. A between-patient disinfection method to control water line contamination and biofilm inside dental units. Journal of Hospital Infection. 2204; 56(4):297-304. doi: https://doi.org/10.1016/j.jhin.2004.01.015.

10. Kedjarune U, Kukiattrakoon B, Yapong B, Chowanadisai S, Leggat PA. Bacterial aerosols in the dental clinic: effect of time, position and type of treatment. International Dental Journal. 2000; 50(2):103-107. doi: https://doi.org/10.1002/j.1875-595x.2000.tb00807.x

11. Yi Yi Yong, Gary D, Wee Sim C. Biofilm formation by staphylococci in health-related environments and recent reports on their control using natural compounds. Critical Reviews in Microbiology. 2019; 45(2): 201-222. doi: https://doi.org/10.1080/1040841X.2019.1573802.

12. Rautemaa R, Nordberg A, Wuolijoki-Saaristo K, Meurman JH. Bacterial aerosols in dental practice-a potential hospital infection problem? J Hosp Infect. 2006; 64:76-81. doi: https:// doi.org/10.1016/j.jhin.2006.04.011.

13. Maya JJ, Ruiz SJ, Pacheco R, Valderrama SL, Villegas MV. Role of chlorhexidine in the prevention of health care related infections. Infectio. 2011; 5(2):98-107. 